\title{
MORFOGÊNESE E DINÂMICA DO PERFILHAMENTO DE Panicum maximum JACQ. cv. TANZÂNIA-I SOB PASTEJO ${ }^{1}$
}

\author{
Morphogenesis and tillering dynamics of Panicum maximum Jacq. cv. Tanzânia-I under grazing
}

\author{
Milena Biasi Ferlin², Valéria Pacheco Batista Euclides ${ }^{3}$, Beatriz Lempp ${ }^{4}$, Manoel Carlos Gonçalves ${ }^{5}$, \\ Antonio Carlos Cubas 6
}

\begin{abstract}
RESUMO
Avaliou-se o efeito de dois resíduos de forragem pós-pastejo quanto às características morfogênicas de folhas e perfilhos e estrutura do relvado de Panicum maximum Jacq. cv. Tanzânia-I até os 35 dias após a desfolha, em duas estações do ano, verão e outono. Utilizou-se o delineamento de blocos completos casualizados, com os resíduos de forragem na parcela principal, estação do ano nas subparcelas e dias após o pastejo nas sub-subparcelas, com três repetições. Os resíduos de forragem não influenciaram as taxas de aparecimento e alongamento de folhas, bem como duração do alongamento de folhas nos perfilhos residuais e quantidade de perfilhos. Os números médios de lâminas foliares e de perfilhos basilares novos apresentam-se semelhantes no transcorrer dos dias de descanso no verão e outono. Já o número de perfilhos aéreos novos, no verão, decresceu com os dias de descanso e, no outono, manteve-se mais constante. No outono, o comprimento de lâminas foliares aumentou linearmente até o $35^{\circ}$ dia de descanso. Já no verão, as lâminas foliares atingiram o crescimento máximo em torno de 30 dias.
\end{abstract}

Termos para indexação: Resíduos de forragem, estações do ano, dias após pastejo.

\section{ABSTRACT}

The effect of two forage residuals after grazing was evaluated as to morphogenic traits of leaves and tillers and forage structure of Panicum maximum Jacq. cv. Tanzania-I until the 35 days after defoliation, within two year seasons, summer and fall. The experimental design was a complete randomized blocks, with forage residuals in the main plots, year season in the sub-plot, and days after grazing in the sub-sub-plot, with three replications. The forage residuals did not affect the rates of appearance and lengthening of leaves in the residual tillers, and into the tillers quantity. The average number of leaf blades and new basal tillers keep a similar performance throughout the summer and autumn days. Therefore the number of new aerial tillers, during the summer, decreased as a function of days of rest being that in the fall remained more constant. In the autumn, the length of leaf blades grew linearly until the 35th resting day. Therefore in the summer the leaf blades enhanced maximum growth around 30 days.

Index terms: Forage residuals, year seasons, days after grazing.

\section{(Recebido para publicação em 15 de julho de 2005 e aprovado em 7 de dezembro de 2005)}

\section{INTRODUÇÃO}

A recuperação rápida das plantas forrageiras após a desfolhação tem papel importante no manejo da pastagem, já que a maior produtividade se deve principalmente à maior rapidez no processo de rebrotação. A reação da planta à desfolhação usualmente envolve mais de uma característica adaptativa, as quais podem ser fisiológicas ou morfológicas: a curto prazo se tem uma adaptação fisiológica à restrição de carboidratos durante o crescimento da planta e, a longo prazo, ocorre a plasticidade morfológica para redução da probabilidade de desfolhação, o que em conseqüência confere tolerância da planta ao pastejo (BRISKE, 1996).
As principais relações entre características morfogênicas e estruturais das gramíneas forrageiras em estádio vegetativo foram apresentadas por Chapman \& Lemaire (1993). As morfogênicas, tais como alongamento de folhas, aparecimento de folhas e duração de vida das folhas, embora sejam determinadas geneticamente, são influenciadas pelo ambiente e determinam as principais características estruturais do relvado: tamanho de folha, densidade populacional de perfilhos e número de folhas vivas por perfilho.

Nesses termos, os pastos podem ser considerados como sistemas dinâmicos, onde alterações na morfogênese determinam modificações na estrutura do dossel, resultando em alterações no índice de área foliar (IAF) e, conseqüentemente, na qualidade da luz interceptada.

\footnotetext{
Parte da tese de Mestrado do primeiro autor.

2 Mestre em Agronomia, fiscal estadual agropecuária - Agência Estadual de Defesa Animal e vegetal/IAGRO - Rua Delfino Garrido, 425 - Jardim Ouro verde - 79.833-050 - Dourados, MS

${ }^{3} \mathrm{PhD}$, pesquisadora Embrapa Gado de Corte - Cx. P. 154 - 79.002-970 - Campo Grande, MS

${ }^{4}$ Doutora em Zootecnia, Professora da Universidade Federal do Mato Grosso do Sul/UFMS - Cx. P. 533 - 79.804-970 - Dourados, MS.

${ }^{5}$ Doutor em Agronomia, Professor da Universidade Federal do Mato Grosso do Sul/UFMS - Cx. P. 533 - 79.804-970 - Dourados, MS

${ }^{6} \mathrm{PhD}$ em Melhoramento Genético Animal, professor UFMS
} 
Dentro desse contexto, o IAF aparece como sendo o maior integrador de características estruturais do relvado, sendo que o primeiro efeito da desfolhação, conforme a prática de manejo empregada, é possibilitar a variação no IAF entre dois extremos, pré e pós-desfolha (LEMAIRE, 2001). Assim, a taxa de aparecimento foliar desempenha o papel central na morfogênese e, por consequiência, no IAF, pois influencia diretamente cada um dos três componentes da estrutura do pasto: tamanho de folha, densidade populacional de perfílhos e número de folhas vivas por perfílho (NABINGER \& PONTES, 2001).

Lemaire (2001) citou que sob desfolhas freqüentes e intensas, com altas taxas de lotação contínua, há pouca competição por luz devido à constante remoção de área foliar pelos animais. De forma contrária, sob desfolha pouco freqüente, como em alguns casos de lotação intermitente, a competição por luz aumenta progressivamente durante o período de rebrotação. Dessa forma, cada evento de desfolha corresponde primeiramente a uma rápida mudança na quantidade e qualidade da luz que penetra no dossel forrageiro e, em segundo lugar, a uma rápida mudança em sua arquitetura à medida que a intensidade de desfolha vai se tornando mais severa.

O perfilhamento é dependente de condições internas e externas à planta, sendo regulado principalmente pelo genótipo, balanço hormonal, florescimento, luz, temperatura, fotoperíodo, água, nutrição mineral e desfolhação (LANGER, 1963). O potencial de perfilhamento de um genótipo é determinado pela sua velocidade de emissão de folhas, pois a cada folha formada corresponde a formação de uma gema axilar com potencial de geração de um perfilho (MATTHEW et al., 1999).

Espécies de gramíneas perenes contêm dois grupos de perfilhos: perfilhos basilares, que se originam da base da planta e, mais tarde, possuem seu próprio sistema radicular, e perfilhos aéreos, que surgem a partir de nós superiores dos colmos em florescimento ou com meristema decapitado e que não desenvolveram sistema radicular independente (LOCH, 1985).

Os perfilhos também podem ser classificados como remanescentes, os que sobreviveram ao último pastejo; como novos, os que apareceram após o pastejo, e como decapitados, os que sobreviveram ao pastejo, mas tiveram seus meristemas apicais removidos. A eliminação das gemas apicais determina a morte dos perfilhos. Novas brotações surgirão a partir do desenvolvimento de gemas basilares ou laterais, dando origem a novos perfilhos, porém com recuperação da área foliar mais lenta (GOMIDE, 1988).

Conduziu-se o presente experimento, objetivando estudar o efeito do resíduo de forragem pós-pastejo em
Panicum maximum Jacq. cv. Tanzânia-I quanto às características morfogênicas de folhas e de perfilhos em duas estações do ano, verão e outono.

\section{MATERIAL E MÉTODOS}

$\mathrm{O}$ experimento foi conduzido em uma área da Embrapa Gado de Corte, em Campo Grande-MS, localizada

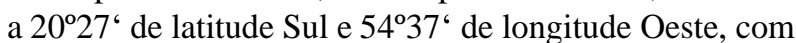
altitude de $530 \mathrm{~m}$ acima do nível do mar. O clima, segundo a classificação de Köppen, é do tipo tropical chuvoso de savana, subtipo AW. No primeiro período experimental, 17/01 a 21/02/01, verão, a insolação foi de 232,3 h de luz, a precipitação pluvial total foi de $180,5 \mathrm{~mm}$ e a umidade relativa média foi de $79,6 \%$. A temperatura média máxima permaneceu em torno de $32,4^{\circ} \mathrm{C}$ e a mínima em $21,1^{\circ} \mathrm{C}$. No segundo período experimental, 25/04 a 31/05/01, outono, a insolação foi de $259,36 \mathrm{~h}$ de luz, a precipitação pluvial total foi de $101,6 \mathrm{~mm}$ e a umidade relativa média foi de $72,2 \%$. A temperatura média máxima foi de $28,1^{\circ} \mathrm{C}$ e a mínima, $16,9^{\circ} \mathrm{C}$. O solo onde foi implantado o experimento é classificado como Latossolo Vermelho Distrófico típico, caracterizado por textura argilosa, $\mathrm{pH}$ ácido, baixa saturação por bases, alta concentração de alumínio e baixo teor de fósforo.

$\mathrm{O}$ solo da área experimental apresentou as seguintes características químicas, 0-15cm: pH 6,47 SMP; pH 5,82 $\mathrm{CaCl}_{2}$; fósforo - Mehlich-1 $5,63 \mathrm{mg} / \mathrm{dm}^{3}$; potássio Mehlich-1 136,16 mg/dm 3 ; alumínio $0,35 \mathrm{cmol} / \mathrm{dm}^{3} ; \mathrm{H}+\mathrm{Al}$ $3,38 \mathrm{cmol}_{\mathrm{c}} / \mathrm{dm}^{3}$; soma de bases $6,34 \mathrm{cmol} / \mathrm{dm}^{3}$; CTC 9,76 $\mathrm{cmol}_{\mathrm{c}} / \mathrm{dm}^{3}$; CTC efetiva $6,41 \mathrm{cmol}_{\mathrm{c}} / \mathrm{dm}^{3}$; saturação por alumínio $0,35 \%$; saturação por bases $65,32 \%$; matéria orgânica $37,8 \mathrm{~g} / \mathrm{dm}^{3}$.

Como histórico da área tem-se: semeadura de $P$. maximum cv. Tanzânia - I realizada em 1998, com 2,5 kg/ha de sementes puras viáveis; quantidades de calcário e de adubos utilizados anualmente para a manutenção do nível de fertilidade entre $70-80 \%$ de saturação por bases, $8-12$ $\mathrm{mg} / \mathrm{dm}^{3}$ de fósforo (P-Mehlich 1) e $80-100 \mathrm{mg} / \mathrm{dm}^{3}$ de potássio e aplicação de $200 \mathrm{~kg} / \mathrm{ha} /$ ano de N, parcelada em duas vezes, novembro e janeiro. Foram avaliados três piquetes no verão e três piquetes no outono, de 0,188 ha cada, aleatoriamente, em um sistema de pastejo rotacionado, com ciclos de pastejo de 42 dias, sendo o período de descanso de 35 dias e de ocupação de 7 dias.

$\mathrm{O}$ delineamento experimental utilizado foi em blocos completos casualizados com os tratamentos no esquema de parcelas subsubdivididas, com três repetições. As parcelas foram os resíduos de forragem: resíduo alto (RA)-4,2 t/ha de MS (verão-4.208,1 kg/ha e outono-4.174,7 kg/ha) e resíduo baixo (RB)-3,5 t/ha de MS (verão-3.582,4 kg/ha e outono- 
$3.843,1 \mathrm{~kg} / \mathrm{ha})$. As estações do ano, verão (17/01/01 a 21/02/ 01) e outono (25/04/01 a 31/05/01), constituíram as subparcelas. Já as subsubparcelas foram constituídas pelos dias em que se realizaram as avaliações após o pastejo.

O rebaixamento da forragem aos níveis de resíduos pré-fixados foi efetuado por novilhos com idade entre 1824 meses e peso aproximado de $400 \mathrm{~kg}$. Após a saída dos animais dos piquetes, foram iniciadas as avaliações, simultaneamente, nos seis módulos de pastejo. No início de cada período de descanso da pastagem foram identificadas as plantas para a avaliação da dinâmica de perfilhamento e perfilhos para as avaliações das características morfogênicas e estruturais. Foram tomados ao acaso 30 perfilhos por piquete, sendo 3 novos e 3 remanescentes em cada uma das cinco linhas transectas. Os perfilhos foram identificados com anéis plásticos e, para permitir melhor visualização no campo, ao lado de cada perfilho foi fixada uma estaca de ferro com uma fita numerada colorida. As observações de cada perfilho foram iniciadas no segundo dia após o término do período de ocupação, sendo que a partir do quinto dia foram realizadas três vezes por semana, durante o período de descanso da forrageira, perfazendo 15 avaliações.

A partir desses valores, calcularam-se as seguintes características: taxa de alongamento foliar nos perfilhos remanescentes - $\mathrm{TAlF}_{\mathrm{PR}}$ e novos - $\mathrm{TAlF}_{\mathrm{PN}}$ (cm/dia.perfilho), obtida pela divisão da diferença entre os comprimentos de duas avaliações sucessivas das lâminas foliares de um perfilho pelo número de dias; taxa de aparecimento de folhas nos perfilhos remanescentes - $\mathrm{TApF}_{\mathrm{PR}}$ e novos $\mathrm{TApF}_{\mathrm{PN}}$ (folha/dia.perfilho), obtida pela divisão do número de folhas novas surgidas durante o período de avaliação pelo número de dias do experimento, por perfilho; duração do alongamento das lâminas foliares nos perfilhos remanescentes $-\mathrm{DAlF}_{\mathrm{PR}}$ e novos $-\mathrm{DAlF}_{\mathrm{PN}}$ (dias/perfilho), obtida pela divisão do somatório do número de dias em que as folhas alongam pelo número de folhas que estiveram em crescimento, por perfilho; comprimento médio de lâminas foliares nos perfilhos remanescentes $-\mathrm{CLF}_{\mathrm{PR}} \mathrm{e}$ novos - $\mathrm{CLF}_{\mathrm{PN}}(\mathrm{cm})$, sendo essa a média aritmética do comprimento das lâminas foliares do perfilho; número de lâminas foliares vivas nos perfilhos remanescentes - $\mathrm{NLF}_{\mathrm{PR}}$ e novos - NLF $_{\mathrm{PN}}$ (lâminas foliares), média aritmética do número de folhas por perfilho. A taxa de senescência - TS (cm.dia/perfilho) foi determinada pela divisão dos somatórios das senescências foliares pelo número de dias do experimento, por perfilho.

Para a avaliação da dinâmica de perfilhamento foram realizadas contagens aos 6, 13, 20, 27 e 34 dias de descanso da pastagem, utilizando-se dez touceiras em cada piquete, distribuídas em quatro linhas transectas, contendo três, duas, duas e três plantas. Para a identificação das touceiras, utilizou-se arame com fita numerada e cercou-se com barbante cada uma das touceiras. Aos seis dias de descanso, avaliaram-se perfilhos basilares novos totais $-\mathrm{PB}_{\mathrm{N}} \mathrm{T}$ (unidade), perfilhos aéreos novos totais $-\mathrm{PA}_{\mathrm{N}} \mathrm{T}$ (unidade), perfilhos basilares remanescentes totais $-\mathrm{PB}_{\mathrm{R}} \mathrm{T}$ (unidade), perfilhos aéreos remanescentes totais $-\mathrm{PA}_{\mathrm{R}} \mathrm{T}$ (unidade) e perfilhos decapitados, com meristema apical removido - PDEC (unidade). Os dados de número de perfilhos aéreos foram transformados [raiz de $(\mathrm{x}+0,5)]$ para análise estatística, sendo posteriormente retransformados.

A análise dos dados obtidos foi realizada utilizandose o programa SAS PROC GLM (General Linear Models), do SAS Institute (1993). As interações significativas foram desdobradas e as médias foram comparadas pelo teste de Tukey a 5\% de probabilidade. Optou-se pelo não desdobramento das interações de segunda ordem, pelo fato da explicação biológica ser de difícil interpretação. Para o ajuste das curvas de regressão foi utilizado o programa Origin 3.0 (ORIGIN 3.0, 1991-1993). A escolha do melhor modelo baseou-se no coeficiente de determinação e na significância dos coeficientes de regressão.

\section{RESULTADOS E DISCUSSÃO}

Observou-se interação significativa entre estação do ano e dias de descanso para $\mathrm{TAlF}_{\mathrm{PR}}$ e $\mathrm{TAlF}_{\mathrm{PN}}$ (Figura 1) e, para $\mathrm{TAlF}_{\mathrm{PN}}$, entre resíduos de forragem e estação do ano. Verificou-se maior $\mathrm{TAlF}_{\mathrm{PN}}$ no verão em relação ao outono, com 3,0 e 2,1 no RB e 3,4 e 2,1 (cm/dia.perfilho) no RA, verão e outono, respectivamente. $\mathrm{A} \mathrm{TAlF}_{\mathrm{PR}}$ não foi influenciada pelos resíduos de forragem, sendo em média de $2,7 \mathrm{~cm} /$ dia.perfilho.

Beretta et al. (1999), ao avaliarem a cv. Tanzânia-I, obtiveram TAlF de 1,13 e 1,54 cm/dia.folha nos períodos seco e chuvoso, respectivamente, sendo estas menores que aquelas obtidas neste estudo. Porém, Gomide \& Gomide (2000), em casa-de-vegetação, encontraram maiores TAlF, 7,07 cm/dia.perfilho, que aquelas obtidas neste trabalho. Já Barbosa (2000) verificou que as taxas de alongamento foliar não diferiram entre resíduos de forragem, 3,6 e 2,3 t/ha de MS, e tipos de perfilhos, novo e remanescente, para a cv. Tanzânia-I.

No verão as TApF foram maiores do que as observadas no outono, em média $11,1 \%$ nos perfilhos novos e $37,5 \%$ nos remanescentes, provavelmente como reflexo do estresse hídrico da planta ocorrido no outono. A TApF é uma característica plástica da planta, sendo que em situação de 
estresse tende a decrescer (NABINGER \& PONTES, 2001). $\mathrm{Na}$ forragem manejada com RB ocorreu maior TApF nos perfilhos novos e remanescentes do que na com RA. Resultado semelhante foi observado por Barbosa (2000). A TApF de 0,094 folhas/perfilho para a cv. Tanzânia-I observada por Gomide \& Gomide (2000) foi similar à TApF $\mathrm{PN}_{\mathrm{PN}}$ deste estudo, no verão, como pode ser verificado na Tabela 1 .

A DAlF ${ }_{\mathrm{PN}}$ foi maior no RB no outono em relação ao RA no verão. Nos perfilhos remanescentes a DAlF foi em média de 7,4 dias/perfilho. Já Barbosa (2000) observou uma DAlF menor no menor resíduo de forragem. As taxas de senescência apresentaram coeficiente de variação muito alto, verificando-se os seguintes valores: 0,$86 ; 1,43 ; 1,0$; 1,$3 ; 1,4$ e $0,9 \mathrm{~cm} /$ dia.perfilho para os perfilhos novos, remanescentes, RB, RA, verão e inverno, respectivamente.

$\mathrm{Na}$ Tabela 2 pode ser observado o desdobramento da interação resíduo de forragem $\mathrm{x}$ estação do ano para as variáveis $\mathrm{CLF}_{\mathrm{PN}}, \mathrm{NLF}_{\mathrm{PR}}$ e as médias do $\mathrm{CLF}_{\mathrm{PR}}$ obtidas para os resíduos de forragem. $\mathrm{O} \mathrm{CLF}_{\mathrm{PR}}$ diferiu entre os resíduos de forragem, sendo que as lâminas foliares do RA apresentaram os maiores comprimentos. Já Barbosa et al. (2002) não verificaram diferenças significativas entre os resíduos de forragem para o CLF por perfilho aos 35 dias.

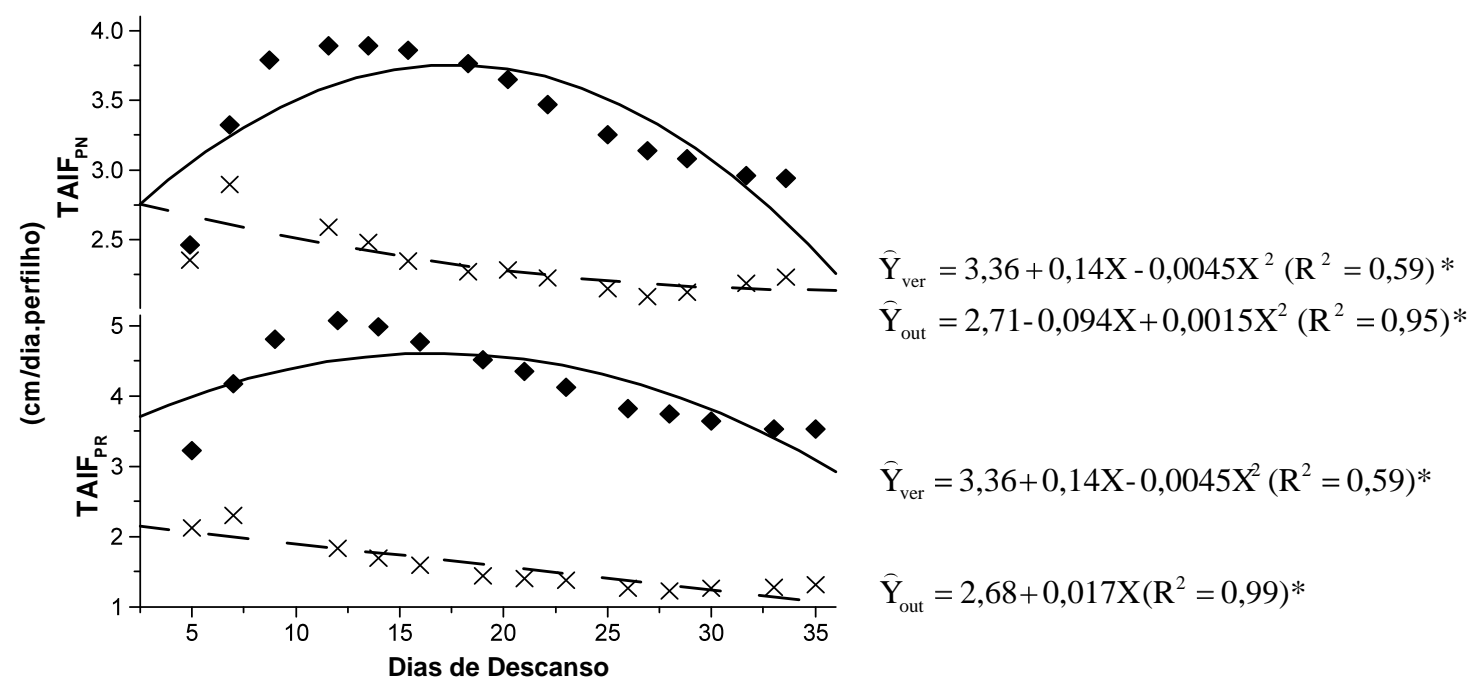

FIGURA 1 - Taxa de alongamento de lâminas foliares de perfilhos novos $\left(\mathrm{TAlF}_{\mathrm{PN}}\right)$, taxa de alongamento de lâminas foliares de perfilhos remanescentes $\left(\mathrm{TAlF}_{\mathrm{PR}}\right)$ em Panicum maximum cv. Tanzânia-I em função de dias de descanso, verão (ver:— $\longrightarrow$ ) e outono (out:- $\longrightarrow$ ).

TABELA 1 - Taxa de aparecimento de folhas nos perfilhos novos $\left(\mathrm{TApF}_{\mathrm{PN}}\right)$ e duração do alongamento foliar nos perfilhos novos $\left(\mathrm{DAlF}_{\mathrm{PN}}\right)$ para os resíduos de forragem e taxa de aparecimento de folhas nos perfilhos novos $\left(\mathrm{TApF} \mathrm{FN}_{\mathrm{PN}}\right)$, taxa de aparecimento de folhas nos perfilhos remanescentes $\left(\mathrm{TApF}_{\mathrm{PR}}\right)$ e duração do alongamento foliar nos perfilhos novos $\left(\mathrm{DAlF}_{\mathrm{PN}}\right)$, para as estações do ano, de Panicum maximum cv. Tanzânia-I.

\begin{tabular}{lll}
\hline Característica & Resíduo Baixo & Resíduo Alto \\
\hline $\mathrm{TApF}_{\mathrm{PN}}$ (folhas/dia.perfilho) & $0,09^{\mathrm{a}}$ & $0,07^{\mathrm{b}}$ \\
$\mathrm{DAlF}$ & $8,7^{\mathrm{bN}}$ \\
\cline { 2 - 3 } $\mathrm{TApF}_{\mathrm{PN}}$ (fias/perfilho) & $9,5^{\mathrm{a}}$ & Outono \\
\cline { 2 - 3 } $\mathrm{TApF}_{\mathrm{PR}}$ (foldias & $0,09^{\mathrm{a}}$ & $0,08^{\mathrm{b}}$ \\
$\mathrm{DAlF}_{\mathrm{PN}}$ (dias/perfia.perfilho) & $0,0594^{\mathrm{a}}$ & $0,0371^{\mathrm{b}}$ \\
\hline
\end{tabular}

\footnotetext{
a,b, diferem entre si pelo teste de Tukey.
} 
Para $\mathrm{CLF}_{\mathrm{PN}}$ e $\mathrm{CLF}_{\mathrm{PR}}$ ocorreu interação entre resíduos de forragem e os dias de descanso. No verão, independente do tipo de perfilho, as lâminas apresentaram-se mais compridas em relação às do outono (Figura 2).

$\mathrm{O} \mathrm{NLF}_{\mathrm{PR}}$ não diferiu significativamente entre resíduos de forragem e estação do ano, sendo ajustado por equação de regressão em função de dias de descanso (Figura 3). Os valores médios máximos e mínimos obtidos para $\mathrm{NLF}_{\mathrm{PR}}(5,1$ e 4,2 folhas) foram semelhantes aos que Santos et al. (1999) obtiveram para a cv. Tanzânia-I submetida a três intervalos entre pastejos, 28, 38 e 48 dias.

TABELA 2 - Comprimento de lâminas foliares nos perfilhos novos $\left(\mathrm{CLF}_{\mathrm{PN}}\right)$ e número de lâminas foliares nos perfílhos remanescentes $\left(\mathrm{NLF}_{\mathrm{PR}}\right)$ para os dois períodos do ano e resíduos de forragem pós-pastejo e as médias para $\mathrm{CLF}_{\mathrm{PR}}$ para s dois resíduos de pastejo de Panicum maximum cv. Tanzânia-I.

\begin{tabular}{|c|c|c|c|c|}
\hline \multirow[t]{2}{*}{ Características } & \multicolumn{2}{|c|}{ Resíduo Baixo } & \multicolumn{2}{|c|}{ Resíduo Alto } \\
\hline & Verão & Outono & Verão & Outono \\
\hline $\mathrm{CLF}_{\mathrm{PN}}(\mathrm{cm})$ & $16,6^{\mathrm{aA}}$ & $13,2^{\mathrm{bA}}$ & $18,2^{\mathrm{aA}}$ & $13,8^{\mathrm{bA}}$ \\
\hline $\mathrm{NLF}_{\mathrm{PR}}$ (lâminas foliares) & $4,9^{\mathrm{aA}}$ & $4,2^{\mathrm{bA}}$ & $5,4^{\mathrm{aA}}$ & $4,3^{\mathrm{bA}}$ \\
\hline $\mathrm{CLF}_{\mathrm{PR}}(\mathrm{cm})$ & \multicolumn{2}{|c|}{$21,8^{\mathrm{B}}$} & \multicolumn{2}{|c|}{$24,0^{\mathrm{A}}$} \\
\hline
\end{tabular}

a,b, compara na linha, estações do ano dentro de cada resíduo de forragem pós-pastejo, ${ }^{\mathrm{A}, \mathrm{B}}$, compara na linha, resíduo de forragem dentro da mesma estação do ano, pelo teste de Tukey a 5\%.

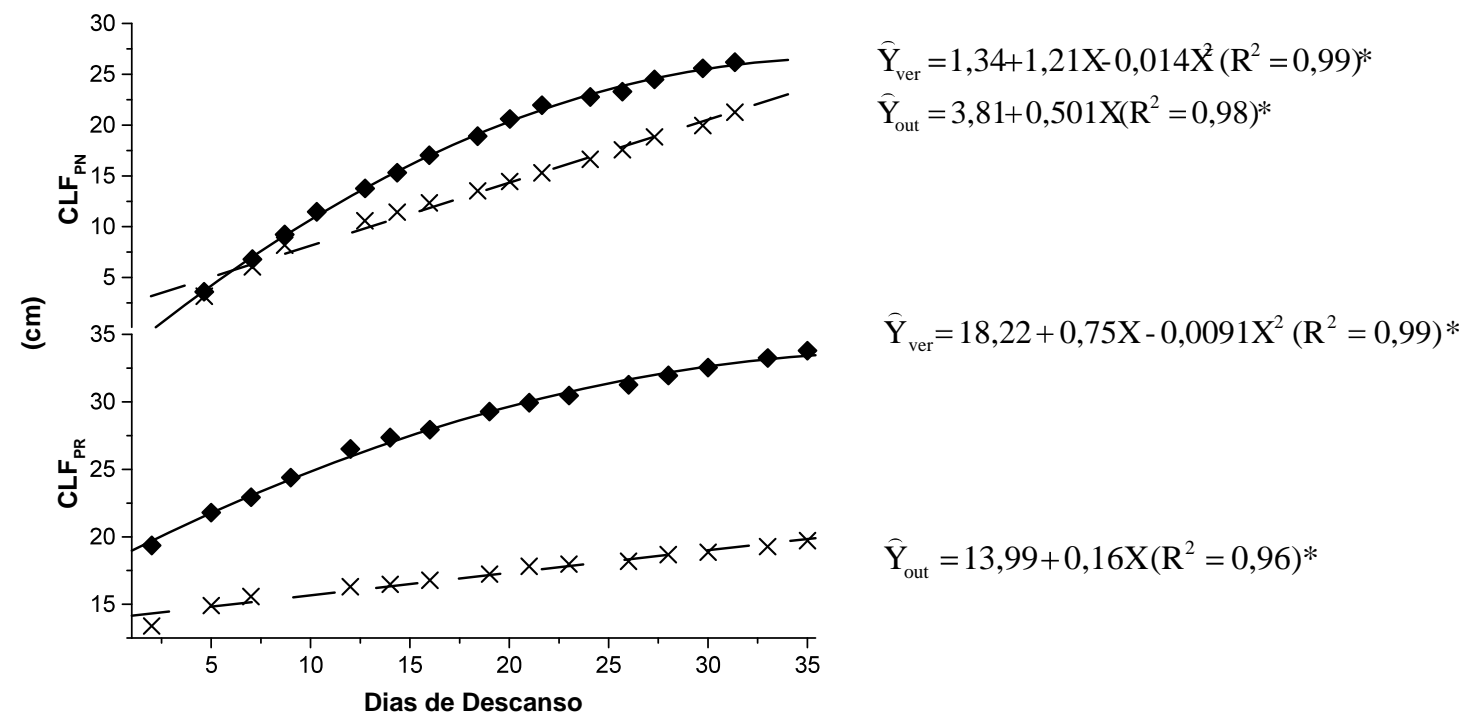

FIGURA 2 - Comprimento de lâminas foliares de perfilhos novos $\left(\mathrm{CLF}_{\mathrm{PN}}\right)$ e perfilhos remanescentes $\left(\mathrm{CLF}_{\mathrm{PR}}\right)$ de Panicum maximum cv. Tanzânia-I em função dos dias de descanso, no verão (ver:—— ) e outono (out:- $—$ x). 
Para $\mathrm{NLF}_{\mathrm{PN}}$ ocorreu interação significativa entre os resíduos pós-pastejo e os dias de descanso e entre as estações do ano e os dias de descanso (Figura 4). $\mathrm{O} \mathrm{NLF}_{\mathrm{PN}}$ apresentou-se máximo no $19^{\circ}$ dia de descanso, no verão, e no $21^{\circ}$ dia, no outono. O NLF estimado foi de 2,9 e 3,7 para o RB e 2,9 e 3,4 para o RA, e de 2,8 e 3,3 no verão e 2,9 e 3,7 no outono, respectivamente, para o início do período de descanso (segundo dia) e para o $35^{\circ}$ dia de descanso.

Esses resultados, em especial no outono, estão em concordância com os encontrados por Gomide \& Gomide (2000) para a cv. Tanzânia, em que o número médio de folhas verdes por perfilho estabilizou-se em 3,5 no crescimento de rebrota. O NLF é uma característica genética como o número de perfilhos, porém menos influenciado pelo ambiente.

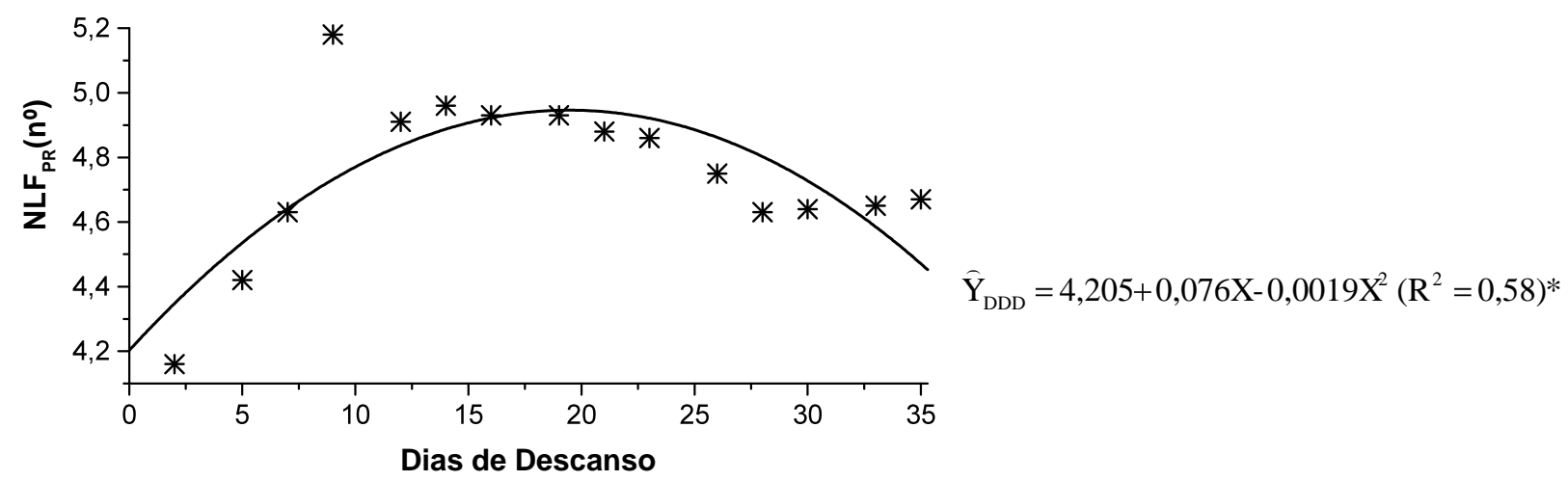

FIGURA 3 - Número de lâminas foliares de perfilhos remanescentes $\left(\mathrm{NLF}_{\mathrm{PR}}\right)$ de Panicum maximum cv. Tanzânia-I em função dos dias.

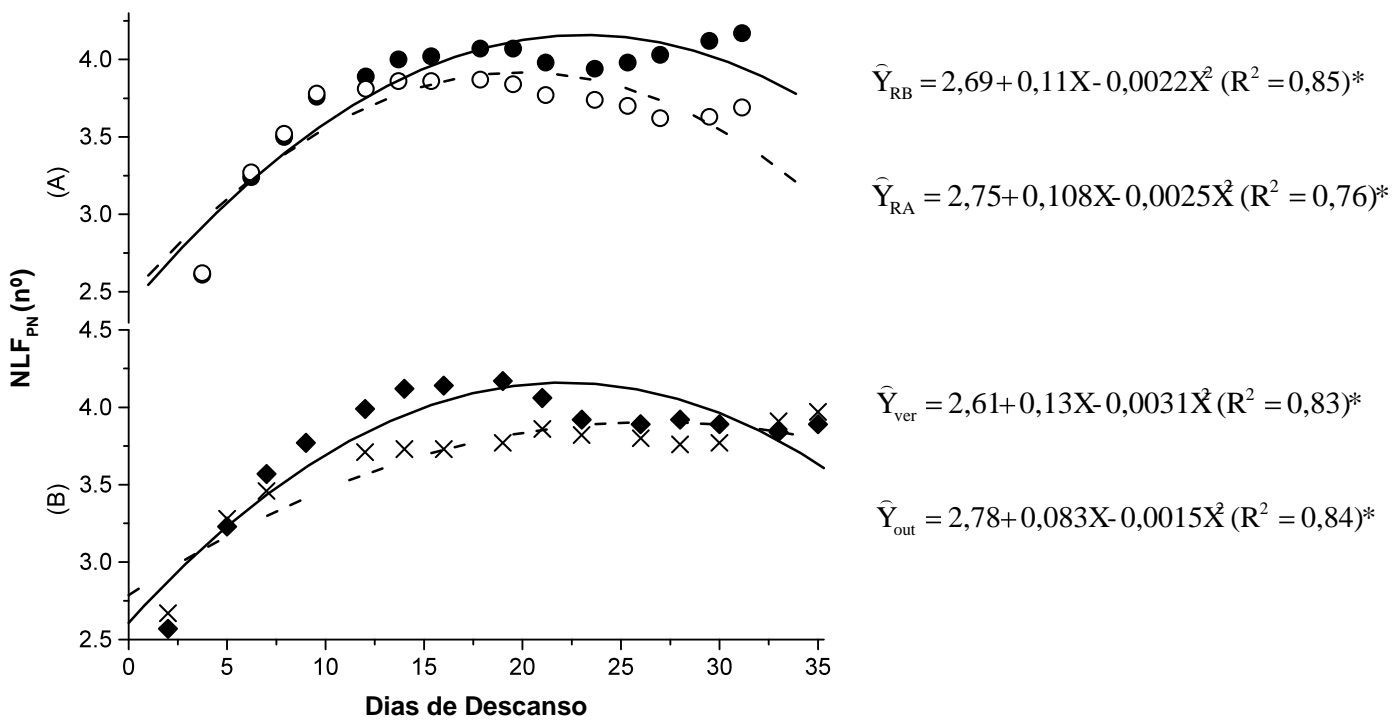

FIGURA 4 - Número de lâminas foliares dos perfilhos novos $\left(\mathrm{NLF}_{\mathrm{PN}}\right)$ de Panicum maximum cv. Tanzânia-I. (A): interação resíduo x dias de descanso; (B): interação estação x dias de descanso no resíduo de forragem baixo (RB:-——.), resíduo de forragem alto (RA: $\longrightarrow$ ), verão (ver:——) e outono (out:- $\longrightarrow$ x ). 
Os números de $\mathrm{PB}_{\mathrm{N}}, \mathrm{PB}_{\mathrm{N}} \mathrm{T}, \mathrm{PB}_{\mathrm{R}} \mathrm{T}, \mathrm{PA}_{\mathrm{R}} \mathrm{T}$ e PDEC não foram influenciados pelos resíduos de forragem, sendo as médias gerais de 6,$5 ; 134,7 ; 32,6 ; 10,4$ e 2,3 perfilhos/touceira, respectivamente. $\mathrm{O} \mathrm{NPA}$ apresentou interação significativa entre os resíduos de forragem e a estação. Independente do resíduo de forragem, o $\mathrm{NPA}_{\mathrm{N}}$ foi superior no outono. Também, no outono, se observou maior $\mathrm{NPA}_{\mathrm{R}} \mathrm{T}, \mathrm{NPB}_{\mathrm{R}} \mathrm{T}$ e o NPDEC em relação ao verão (Tabela 3). Estes resultados estão associados à eliminação da gema apical com conseqüente redução do efeito da auxina nas gemas laterais.

Para a $\operatorname{RNPA}_{\mathrm{N}}\left[\right.$ raiz quadrada $\left.\left(\mathrm{NPA}_{\mathrm{N}}+0,5\right)\right]$, houve interação significativa entre estações do ano e dias de descanso. No verão esse número manteve-se praticamente constante, com poucos perfilhos; já, no outono, apresentou número inicial bem superior com queda acentuada até o $27^{\circ}$ dia e a partir desta data estabilizou-se, com valores levemente superiores no verão (Figura 5).

A pequena quantidade de perfilhos aéreos observada no verão está relacionada com o baixo número de perfilhos decapitados. Assim, o efeito da dominância apical limitou a emissão de perfílhos das gemas axilares, o que não ocorreu no outono, quando houve intenso perfilhamento aéreo. A possível explicação para a concentração do perfilhamento aéreo no outono relaciona-se com a ocorrência da fase reprodutiva da gramínea que aconteceu nos meses de abril e maio, quando foi visível a emissão de panículas, provocando a elevação do meristema apical e facilitando sua remoção, ocorrendo forte emissão de perfilhos aéreos. Para $\mathrm{NPB}_{\mathrm{N}}$ ocorreu interação significativa entre os resíduos pós-pastejo e os dias de descanso, havendo queda no aparecimento dos perfilhos com o decorrer dos dias de descanso (Figura 6).

TABELA 3 - Número de perfilhos aéreos novos $\left(\mathrm{NPA}_{\mathrm{N}}\right)$, aéreos novos totais $\left(\mathrm{NPA}_{\mathrm{N}} \mathrm{T}\right)$, aéreos remanescentes totais $\left(\mathrm{NPA}_{\mathrm{R}} \mathrm{T}\right)$, basilares remanescentes totais $\left(\mathrm{NPB}_{\mathrm{R}} \mathrm{T}\right)$ e decapitados (NPDEC) por touceira de Panicum maximum cv. Tanzânia-I manejado em dois resíduos de forragem pós-pastejo.

\begin{tabular}{lllll}
\hline Características & \multicolumn{3}{c}{ Resíduo Baixo } & Resíduo Alto \\
\cline { 2 - 5 } & Verão & Outono & Verão & Outono \\
\hline $\mathrm{NPA}_{\mathrm{N}}$ & $0,3^{\mathrm{aB}}$ & $3,9^{\mathrm{aA}}$ & $0,7^{\mathrm{aB}}$ & $21,5^{\mathrm{bA}}$ \\
$\mathrm{NPA}_{\mathrm{N}} \mathrm{T}$ & $1,7^{\mathrm{aB}}$ & $30,9^{\mathrm{aA}}$ & $3,9^{\mathrm{aB}}$ & \\
$\mathrm{NPA}_{\mathrm{R}} \mathrm{T}$ & $0,1^{\mathrm{b}}$ & & $13,2^{\mathrm{a}}$ & \\
$\mathrm{NPB}_{\mathrm{R}} \mathrm{T}$ & $118,8^{\mathrm{b}}$ & & $150,6^{\mathrm{a}}$ & \\
$\mathrm{NPDEC}$ & $0,4^{\mathrm{b}}$ & & $20,3^{\mathrm{a}}$ & \\
\hline
\end{tabular}

A,B , compara na linha, estação dentro de cada resíduo de forragem, a,b, compara na linha, resíduo de forragem dentro da mesma estação do ano, pelo teste de Tukey a $5 \%$.

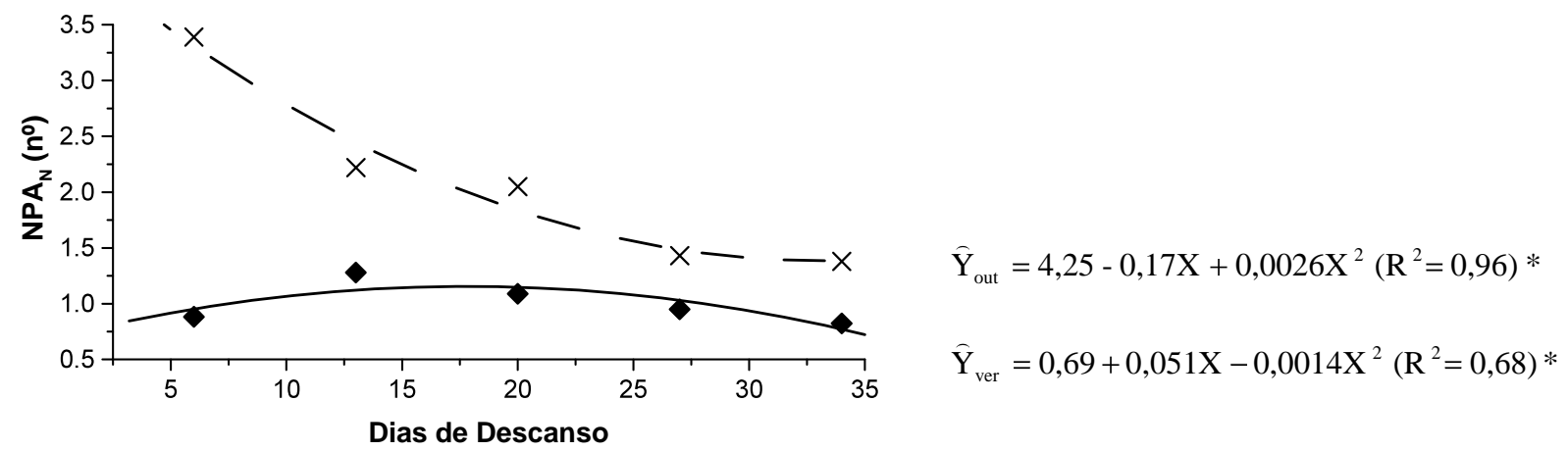

FIGURA 5 - Número de perfilhos aéreos novos $\left(\mathrm{NPA}_{\mathrm{N}}\right)$ de Panicum maximum cv. Tanzânia-I em função da interação: períodos do ano x dias de descanso, no verão (ver:

$\checkmark$ ) e outono (out: $\mathrm{x})$. 


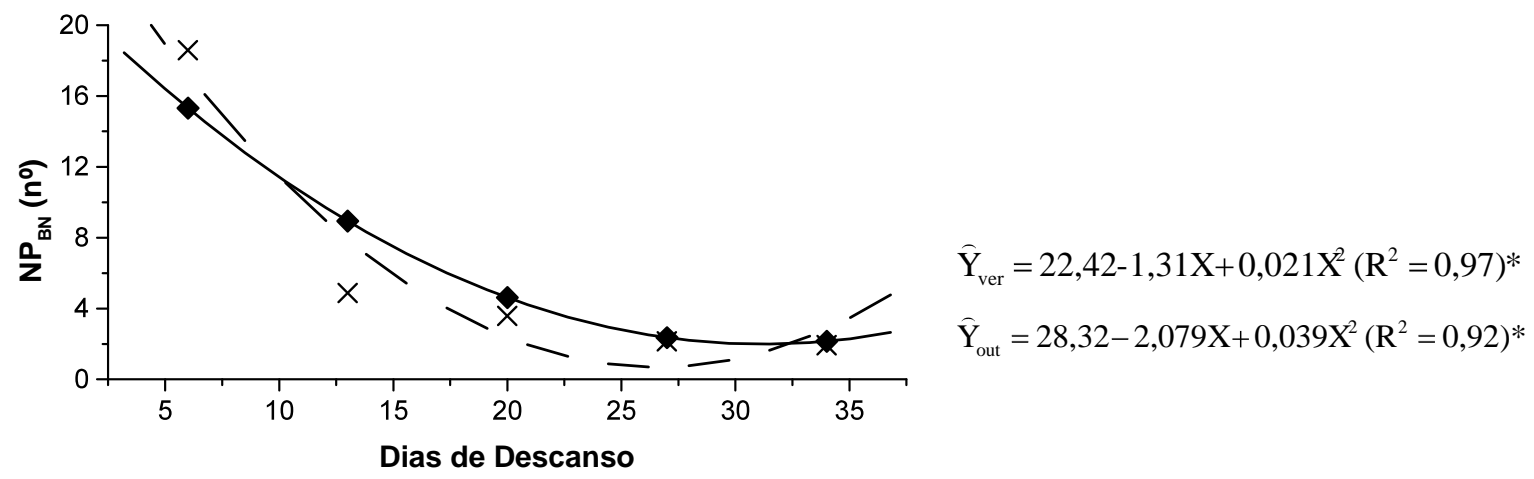

FIGURA 6 - Número de perfilhos basilares novos $\left(\mathrm{NPB}_{\mathrm{N}}\right)$ de Panicum maximum cv. Tanzânia-I em função da interação estações do ano x dias de descanso, no verão(ver:—— ) e no outono (out:——

Corsi (1984) também verificou intensa concentração na emissão de perfilhos nos primeiros oito dias após o corte em ecotipos de $P$. maximum. Por outro lado, Barbosa et al. (1997), estudando quatro cultivares de $P$. maximum, observaram que o aparecimento de novos perfilhos, tanto basilares quanto aéreos, prolongou-se linearmente até a terceira semana após o corte. A maior quantidade de perfilhos basilares novos observados, principalmente nas primeiras semanas, pode ser resultante do aumento de intensidade luminosa sobre as gemas basilares, estimulando o perfilhamento, como descrito por Lambert (1962) e Youngner (1972).

\section{CONCLUSÕES}

O menor resíduo de forragem promoveu maior número de folhas com menor tempo de alongamento em relação ao resíduo alto.

A época do ano interferiu mais na taxa de alongamento de folhas do que o manejo da pastagem.

No verão, o manejo da forrageira com menor resíduo pode implicar em vegetação jovem, devido à maior taxa de aparecimento e alongamento de lâminas.

O período de descanso de 35 dias foi inferior ao ciclo de vida de lâminas foliares e superior à maior concentração de perfilhos basilares.

\section{REFERÊNCIAS BIBLIOGRÁFICAS}

BARBOSA, M. A. A. F.; CECATO, U.; HONORATO, W. M.; COELHO, E. M. Estudo do perfilhamento do capim Mombaça (Panicum maximum Jacq. cv. Mombaça). In: REUNIẪO ANUAL DA SOCIEDADE BRASILEIRA DE
ZOOTECNIA, 34., 1997, Juiz de Fora. Anais... Juiz de Fora: SBZ, 1997. p. 114-116.

BARBOSA, R. A. Morfogênese de Panicum maximum cv. Tanzânia. 2000. 53 f. Dissertação (Mestrado em Zootecnia) - Universidade Federal de Viçosa, Viçosa, 2000.

BARBOSA, R. A.; NASCIMENTO JÚNIOR, D.; EUCLIDES, V. P. B.; REGAZZI, A. J.; FONSECA, D. M. Características morfogênicas e acúmulo de forragem do capim-tanzânia. Revista Brasileira de Zootecnia, Viçosa, v. 31, n. 2, p. 583593, 2002.

BERETTA, L. G. R.; KANNO, T.; MACEDO, M. C.; SANTOS JÚNIOR, J. D. G.; CORREA, R. M. Morfogênese foliar e taxas de crescimento de pastagem de Panicum maximum cv. Tanzânia -1 em solo dos cerrados. In: REUNIÃO ANUAL DA SOCIEDADE BRASILEIRA DE ZOOTECNIA, 36., 1999, Porto Alegre. Anais... Porto Alegre: SBZ, 1999. CD-ROM.

BRISKE, D. D. Strategies of plant survival in grazed systems: a functional interpretation. In: HODGSON, J.; ILLIS, A. W. (Eds.). The ecology and management of grazing systems. Wallingford: CAB International, 1996. p. 37-68.

CHAPMAN, D. F.; LEMAIRE, G. Morphogenetic and structural determinants of plant regrownth after defoliation. In: INTERNATIONAL GRASSLAND CONGRESS, 17. 1993, Palmerston North, New Zeland. Proceedings... Palmerston North: New Zealand Grassland Association, 1993. p. 95-104. 
CORSI, M. Effects of nitrogen rates and harvesting intervals on dry matter productivity, tillering and quality of tropical grass Panicum maximun Jacq. 1984. 125 f. Thesis (Ph.D.) - Ohio State University, Wooster, 1984.

GOMIDE, C. A. M.; GOMIDE, J. A. Morfogênese de cultivares de Panicum maximum Jacq. Revista Brasileira de Zootecnia, Viçosa, v. 29, n. 2, p. 341-348, 2000.

GOMIDE, J. A. Fisiologia das plantas forrageiras e manejo das pastagens. Informe Agropecuário, Belo Horizonte, v. 13, n. 153/154, p. 11-18, 1988.

LAMBERT, D. A. A study of growth in swards of timothy and meadow fescue: III. the effect of two levels of nitrogen under two cutting treatments. Journal of Agriculture Science, London, v. 59, n. 1, p. 25-32, 1962.

LANGER, R. H. M. Tillering in herbage grasses. Herbage Abstracts, London, v. 33, n. 3, p. 141-148, 1963.

LEMAIRE, G. Ecophysiology of grasslands: dynamics aspects of forage plant populations in grazed swards. In: INTERNATIONAL GRASSLAND CONGRESS, 19., 2001, São Pedro. Proceedings... São Pedro: [s.n.], 2001. p. 29-37.

LOCH, D. S. Tiller development in relation of tropical grasses. In: INTERNATIONAL GRASSLAND CONGRESS, 15., 1985, Kyoto. Proceedings... Kyoto: [s.n.], 1985. p. 264-266.
MATTHEW, C.; ASSUERO, S. G.; BLACK, C. K.; SACKVILLE-HAMILTON, N. R. Tiller dynamcs of grazed swards. In: SIMPÓSIO INTERNACIONAL "GRASSLAND ECOPHISIOLOGY AND GRAZING ECOLOGY”, 1999, Curitiba. Anais... Curitiba: UFPR, 1999. p. 109-133.

NABINGER, C.; PONTES, L. S. Morfogênese de plantas forrageiras e estrutura do pasto. In: REUNIÃO ANUAL DA SOCIEDADE BRASILEIRA DE ZOOTECNIA, 38., 2001, Piracicaba. Anais... Piracicaba: Fealq, 2001. p. 755770 .

ORIGIN 3.0. 1991-1993. Disponível em: <http:// www.picinfor.com.br/index.asp?onde+origin.sap>. Acesso em: 10 fev. 2004.

SANTOS, P. M.; BALSALOBRE, M. A.; CORSI, M. Uso do número de folhas por perfílho no manejo de Panicum maximum cvs. Mombaça e Tanzânia. In: REUNIÃO ANUAL DA SOCIEDADE BRASILEIRA DE ZOOTECNIA, 36., 1999, Porto Alegre. Anais... Porto Alegre: SBZ, 1999. CD-ROM.

SAS INSTITUTE. SAS/STAT user's guide statistics. Versão 6.4. Cary, 1993. 2 v.

YOUNGNER, V. B. Physiology of defoliation and regrowth. In: YOUNGNER, V. B.; McKELL, C. M. (Eds.). The biology and utilization of grasses. New York: Academic, 1972. p. 292-303 